* Mestrando em Direito pela Universidade do Vale do Rio dos Sinos. Graduado em Direito pela Universidade Santa Úrsula. E-mail: christianoribeir@gmail.com

** Pós-Doutora em MadridEspanha. Doutora em Direito pela UFPR. Professora do Programa de Pós-graduação em Direito da UNISINOS. Líder do Grupo de Pesquisa |BioTecJus|. E-mail: taysa_sc@hotmail.com

\section{A Sociedade Civil na Composição da Comissão Técnica Nacional de Biossegurança: dificuldades para formação de uma governança biotecnológica}

\author{
Civil Society in the Composition of \\ Brazilian National Biosafety Technical \\ COMMISSION: DIFFICULTIES FOR A \\ BIOTECHNOLOGY GOVERNANCE
}

\author{
Christiano Dornelles Ribeiro * \\ Taysa Schiocchet $* *$
}

Resumo: O presente artigo analisa os déficits de participação na formação da Comissão Técnica Nacional de Biossegurança, à luz do Estado Democrático Ambiental, que elege a participação da sociedade civil nas políticas de biossegurança como princípio básico. Pretende-se identificar a prevalência do discurso cientificista boundary-maker, que influenciou determinantemente o texto da vigente lei de biossegurança, dividindo as cadeiras da Comissão a partir de três segmentos sociais identificados pelo legislador, a comunidade científica, o governamental e a sociedade civil, hierarquizados nessa sequência, em que se observa o papel menos significativo ao último segmento, cuja escolha foi relegada sem critérios rígidos ao setor governamental. Procura-se descortinar as contradições desse discurso prevalente transformado em lei que relegou à sociedade civil um papel secundário na tomada de decisões, isto em plena vigência da Constituição Democrática de 1988, estabelecendo problemas estruturais de difícil superação. Por fim, expõe-se o impacto da tentativa de regulamentar a escolha dos integrantes da sociedade civil por parte do setor governamental sobre o déficit de participação e de que forma ela contribui para distanciar a CTNBio do propósito de estabelecer a governança biotecnológica, responsiva à sociedade presente e futura, corolário do Estado Democrático Ambiental. A metodologia utilizada é qualitativa e exploratória, com análise bibliográfica e documental.

Palavras-chave: Princípio da participação social. Estado Democrático Ambiental. Verdade científica. Comissão Técnica Nacional de Biossegurança. Governança biotecnológica. 
Abstract: This article analyzes the deficits of society participation in the formation of Brazilian National Biosafety Technical Commission, according to the paradigm of the Democratic Environmental State, which elects the participation of civil society in political biosecurity as a basic principle. Identify the prevalence of scientistic boundary-maker speech, who decisively influenced the text of the current biosafety law, dividing the chairs of Commission in three social segments identified at the law, the scientific community, the government and civil society, straight to this hierarchical sequence, in which the less significant role was given to the last social segment, whose choice was relegated to the government sector with no rigid criteria. Try to uncover the contradictions of this prevalent discourse tuned into law which relegated a secondary role to the civil society in decision-making, at full force of the brazilian Democratic Constitution of 1988, which also created structural problems hard to overcome. Exposes the impact of the attempt to regulate the choice of members of civil society by the government sector over the deficit of participation and how it contributes to distance CTNBio from the purpose of establishing an responsive biotechnological governance, for her present and the future society, corollary of Democratic Environmental State. The methodology is qualitative and exploratory, with bibliographical and documental analysis.

Keywords: Social participation principle. Democratic Environmental State. scientific truth. Brazilian National Biosafety Technical Commission. Biotechnology governance. 


\section{INTRODUÇÃO}

Pode-se afirmar que são recentes a discussão e a regulamentação no Brasil sobre a biossegurança e as medidas necessárias para a proteção da saúde dos trabalhadores envolvidos com o estudo e a aplicação das novas tecnologias, evoluindo mais recentemente para uma preocupação mais ampla, no sentido de alcançar também os impactos sobre o meio ambiente, a economia e a saúde pública.

A legislação brasileira vigente estabeleceu um órgão responsável pelo controle das tecnologias de OGMs, a denominada Comissão Técnica Nacional de Biossegurança, em regra excluindo do processo decisório todos os outros.

Há muito que se realiza a discussão sobre a legalidade da existência da CTNBio, tal como disposta na vigente lei de biossegurança, que lhe garante ampla autonomia, a sua relação aos órgãos de registro, controle e fiscalização tradicionais, a legitimidade de suas decisões, discussão que se iniciou desde o início da vigente lei. ${ }^{1}$ Porém, a composição do colegiado, em si, não tem sido alvo de maiores questionamentos.

Assim, a composição da CTNBio e a efetividade da participação social na formação do colegiado por meio da sociedade civil não tem sido matéria que, até o momento, tenha gerado debate aprofundado da comunidade jurídica, apesar de todo o movimento realizado no Rio+20 em favor do aprimoramento da participação social. ${ }^{2}$

É exatamente este o tema sobre o qual nos propomos tratar no presente artigo: os déficits de participação na composição deste colegiado híbrido, destinado a deliberar, em última e definitiva instância, sobre os casos em que a atividade é potencial ou efetivamente causadora de degradação

\footnotetext{
${ }^{1}$ A lei de biossegurança, assim que entrou em vigor, foi objeto da Ação Direta de Inconstitucionalidade $\mathrm{n}^{\mathrm{o}}$ 3526, ajuizada pelo Procurador-Geral da República em 21 de dezembro de 2005, e nela foi requerida a declaração de inconstitucionalidade dos artigos $6^{\circ}$, inciso VI; $10 ; 14$, incisos IV, VIII, XX, e $\S \S 1^{\circ}$, $2^{\circ}, 3^{\circ}, 4^{\circ}, 5^{\circ}$ e $6^{\circ} ; 16, \S 1^{\circ}$, inciso III, e $\S \S 2^{\circ}, 3^{\circ}, 4^{\circ}, 5^{\circ}, 6^{\circ}$ e $7^{\circ}$; artigos $30,34,35,36,37$ e 39 , todos da Lei de Biossegurança. Nenhum desses artigos se refere especificamente à composição do colegiado, embora se impugne o exercício exclusivo da gestão dos riscos da biotecnologia, diminuindo-se o poder da CTNBio.

${ }^{2}$ A Rio +20 Declaration on Justice, Governance and Law for Environmental Sustainability propugna que os objetivos da conferência fazem parte de um processo dinâmico e integrado, no qual os objetivos econômicos, sociais e ambientais estão intimamente interligados ligados e que: (...)(B) a participação da sociedade na tomada de decisões e acesso à justiça e informação, de acordo com Princípio 10 da Declaração do Rio, incluindo a exploração do valor potencial das provisões tomadas da Convenção de Aarhus, a este respeito.
} 
ambiental, bem como sobre a necessidade de licenciamento ambiental. Aproveitando-se aqui os trabalhos pesquisas realizados durante a elaboração de dissertação de mestrado, no programa de pós-graduação em direito da UNISINOS, o artigo procura descortinar as contradições desse discurso tecnicista/cientificista prevalente transformado em lei, que relegou à sociedade civil um papel secundário na tomada de decisões, isto em plena vigência da Constituição Democrática de 1988, estabelecendo problemas estruturais de difícil superação para o estabelecimento de uma governança biotecnológica. Expõe o impacto da tentativa de regulamentar a escolha dos integrantes da sociedade civil por parte do setor governamental sobre o déficit de participação e de que forma ela contribui para distanciar a CTNBio do propósito de estabelecer a governança biotecnológica, responsiva à sociedade presente e futura, corolário do Estado Democrático Ambiental.

$\mathrm{O}$ trabalho aqui realizado procura também avaliar até que ponto a falta de critérios para escolha de representantes da sociedade civil por parte dos Ministérios, que açodam as escolhas internamente, agrava os déficits de participação verificados desde a lei de biossegurança, descaracterizando os propósitos da criação do colegiado híbrido.

A metodologia utilizada nesta pesquisa é de abordagem qualitativa, com análise bibliográfica e documental.

\section{O PRINCÍPIO DA PARTICIPAÇÃO NO ESTADO DEMOCRÁTICO AMBIENTAL}

A partir da Conferência das Nações Unidas sobre o Meio Ambiente e o Desenvolvimento de 1992, a chamada "responsabilidade de grande duração" (CANOTILHO; MORATO LEITE, 2011, p.26) determinou a obrigatoriedade de os Estados (e outras organizações políticas congêneres) adotarem medidas de proteção voltadas à garantia da sobrevivência da espécie humana e da existência condigna das futuras gerações; medidas de proteção e de prevenção adequadas, que limitem ou neutralizem a causação de danos ao ambiente, cuja irreversibilidade total ou parcial gera danos e desequilíbrios negativamente perturbadores da sobrevivência condigna da vida (responsabilidade antropocêntrica), bem como de todas as formas de vida centradas no equilíbrio e estabilidade dos ecossistemas naturais ou transformados (responsabilidade ecocêntrica). 
O Estado de Direito, agora, deve se preocupar com a preservação de um mínimo existencial ecológico, por meio do que deve promover a defesa do núcleo essencial fundamental ao ambiente e qualidade de vida, o que não significa que essa proteção seja absolutizada, sob pena de interditar qualquer espécie de intervenção humana prejudicial ao meio ambiente, mas, por outro lado, garantido a proibição de retrocesso no nível de proteção já assegurado pelos vários complexos normativos-ambientais.

A equidade intergeracional é um dos elementos básicos do Estado Democrático Ambiental, princípio cujo significado básico é obrigar as gerações presentes a incluir como medida de ação e de ponderação os interesses gerações futuras, especialmente quanto irreversibilidade das alterações, esgotamento dos recursos naturais e riscos duradouros (CANOTILHO; MORATO LEITE, 2011, p.28-29); o que está em causa é a inclusão dos interesses, das gerações futuras, nos princípios materiais de atuação política constitucionalmente relevantes.

Sob outra vertente, é inegável a inclusão, especialmente no chamado direito público, da noção de risco, que passou a ter centralidade dogmática e metódica no âmbito do direito constitucional, gradativamente incorpora a delimitação jurídica dos valores limites do risco ambiental, por meio da exigência da proteção do direito ao ambiente segundo o estagio mais avançado da técnica.

Essa assimilação ocorre por meio da conjugação de três princípios: da proporcionalidade dos riscos, da proteção dinâmica do direito ao ambiente e da obrigatoriedade da precaução.

No mesmo sentido, Canotilho e Morato Leite (2011, p.169-170) ao teorizar sobre o Estado de Direito do Ambiente ${ }^{3}$, como uma projeção do devir no presente, como modelo de Estado e de sociedade ambientalmente orientado, com abertura de horizontes de expectativas e de alternativas, que se opõe ao subjetivismo conformista, lançando tanto o Estado quanto o Direito numa perspectiva mais abrangente, comunicando-se necessariamente com a perspectiva da sociedade e da política.

Um modelo de estado assim concebido deve articular os princípios da solidariedade ecológica e social, de modo a atingir o desenvolvimento sustentável, orientado a buscar a igualdade substancial entre os cidadãos,

\footnotetext{
${ }^{3}$ Embora a terminologia difira da utilizada por Canotilho, não identificamos diferença entre essas construções teóricas. Pode-se considerar que são exatamente a mesma coisa.
}

REVISTA DO DIREITO PÚBLICO, Londrina, v.8, n.2, p.9-34, mai./ago.2013 
por meio do uso racional do patrimônio cultural, o que se projeta diretamente na proteção da biodiversidade.

O objeto do Estado Democrático Ambiental (ou do Estado de Direito Ambiental) é o bem ambiental avaliado de forma dinâmica, envolvendo novas conformações, como as novas tecnologias, como a biotecnologia. A unidade do bem ambiental exige uma defesa multitemática a dar conta de sua amplitude, pois o tratamento da complexidade ambiental promove o encontro de alteridades, de diferenças, complexidades de seres e diversificação de identidades; deve militar na formação da consciência ambiental, indispensável ao exercício da responsabilidade compartilhada e a participação pública nos processos ambientalmente relevantes, reconstruindo formas de pensar e reformulando ideias, recuperando a noção de pertença do homem para com a natureza, assim corroborando com a consolidação de normas centradas na satisfação da dignidade humana, para além do próprio ser humano, favorecendo, enfim, institucionalização de mecanismos mais adequados e compatíveis com a natureza diferenciada dos problemas ambientais, concebendo-se uma gestão de riscos cada vez mais aberta ao diálogo, à interação, à negociação, sobretudo, à participação (MORATO LEITE; BELCHIOR, 2010).

A consecução desse Estado de Direito Ambiental (ou o Estado Democrático Ambiental) passa pela tomada de sensibilização global quanto à crise ambiental e exige o exercício da cidadania participativa, em união de esforços da máquina estatal com a coletividade, como forma de responsabilidade solidária e participativa na proteção do meio ambiente, do patrimônio genético e da biodiversidade.

Morato Leite e Belchior (2010, p.176), adaptando abordagem de Canotilho, ainda identifica a existência de princípios estruturantes do Estado de Direito Ambiental, como núcleos essenciais do direito do meio ambiente, garantindo-lhe base e caracterização. Possuem dimensão constitutiva, ao exprimir, indicar, denotar ou constituir uma compreensão global da ordem constitucional, e uma dimensão declarativa, assumindo natureza de superconceitos, vocábulos designantes, utilizados para exprimir a soma de outros subprincípios e de concretizações de normas plasmadas. O autor relaciona como princípios estruturantes do EDA o princípio da participação, da prevenção e da precaução, do poluidor-pagador e da responsabilização como os integrantes dos princípios estruturantes básicos do EDA, e, como não poderia deixar de ser, do próprio direito ambiental. 
A participação social, no Estado Democrático ambiental, é condição de possibilidade desse próprio EDA, possível de se realizar somente a partir da tomada de consciência geral da sociedade, com o constante fortalecimento e aprimoramento das estruturas da sociedade organizada, estimulando-se, pois, a cidadania ambiental, no agir conjunto com a obrigação do Estado em defender o meio ambiente, agir responsivo que depende da libido pela virtude cívica. (BOURDIEU, 2005, p.221-222). A democracia na gestão ambiental abre espaço para a efetividade da participação. A prestação de contas, que já se vê introduzida no mundo anglo-saxão, pela expressão accountable, deverá ser traduzida pela aplicação dos princípios da motivação convincente, ampla e contínua, publicidade, razoabilidade e proporcionalidade. As gerações presentes desejam os Estados como protetores do meio ambiente, seja para as gerações atuais, seja para as gerações que não podem falar ou protestar; eles devem ser os curadores dos interesses das gerações futuras, não constituindo uma utopia distante um Estado de Bem-Estar Sócio Ambiental, possuindo como elemento fundante a própria equidade.

A Declaração do Rio de Janeiro/92, em uma das frases do Princípio 10, afirma que, "no nível nacional, cada indivíduo deve ter acesso adequado a informações relativas ao meio ambiente de que disponham autoridades públicas, inclusive informações sobre materiais e atividades perigosas em suas comunidades". Na mesma linha, importa referir a Convenção sobre o Acesso à Informação, a Participação do Público no Processo Decisório e o Acesso à Justiça em Matéria de Meio Ambiente de Ärhus, em especial o art. $2^{\circ}$, item $3 .^{4}$

A participação ativa das pessoas na comunidade fiscalizando, de uma maneira geral, controlando e tomando iniciativas nos assuntos que lhes dizem respeito ajuda no desenvolvimento da sociedade. Assim também define uma relação de respeito entre o governo e os cidadãos não permitindo uma situação de políticas autoritárias e paternalistas por parte dos governantes (CANOTILHO; MORATO LEITE, 2011, p.181-182). A sociedade civil não tem mais o papel passivo no mundo contemporâneo, como se fosse destinatária de políticas autoritárias ou paternalistas dos governantes. Hoje, cada cidadão que compõe essa sociedade atua - ou deve atuar - efetivamente na fiscalização e no controle das ações governamentais. Pode-se perceber que o ser humano passou a ter consciência da sua transcendental importância

\footnotetext{
${ }^{4}$ Texto disponível no site: http://www.cada.pt/uploads/d98108f2-3272-3e31.pdf.
} 
como sujeito e agente da história, apercebendo-se da sua responsabilidade no processo de desenvolvimento da comunidade a que pertence. A Constituição Federal em vigor, estabelece o paradigma Estado Democrático de Direito, tendo por fundamento dentre outros, a cidadania, a dignidade da pessoa humana, os valores sociais do trabalho e da livre iniciativa e o pluralismo político $\left(\operatorname{art.} 1^{\circ}\right)$. A participação social também pode ser depreendida do artigo 225, caput, da Constituição Federal, na comunhão de deveres de proteção do meio ambiente. (DERANI, 1997, p.226). As modalidades tradicionais do direito de participação política - como o direito de votar e ser votado, a filiação partidária, etc. - não esgotam o exercício da cidadania contemporâneo, sendo necessário aprimorar e criar novas modalidades de participação política, novas maneiras de exercício do direito fundamental do ser humano de "tomar parte no governo de seu país diretamente ou por intermédio de representantes livremente escolhidos" (artigo XXI da Declaração Universal dos Direitos Humanos). Como corolário lógico, ao Poder Público incumbe instituir uma ordem jurídica visando a instrumentalizar uma democracia socialmente participativa, mediante a instituição de instrumentos de participação direta do cidadão de fiscalização e de controle da coisa pública, depreendendo-se disso que o poder pode ser exercido de duas formas: a) mediante os representantes eleitos (Presidente da República, Governador, Prefeito, Deputado etc.); ou b) diretamente pelo povo (plebiscito, referendo, iniciativa popular de projetos de lei e outras formas de participação).

No Capítulo dedicado à Seguridade Social, a Constituição determina expressamente nas ações governamentais, na área de assistência social, a "participação da população, por meio de organizações representativas, na formulação das políticas e no controle das ações em todos os níveis" (Art. 204, II, da CF). Com isso, assegura-se, ao cidadão a prerrogativa de ser parte legítima para propor ação popular, visando a anular ato lesivo ao patrimônio público, à moralidade administrativa, ao meio ambiente e ao patrimônio histórico e cultural (art. 5. ${ }^{\circ}$, LXXIII, da CF).

A existência de um sistema descentralizado e participativo, como nos casos de conselhos e conferências com caráter deliberativo, escapa aos tradicionais mecanismos políticos de decisão e legitimação, tratando-se de espaços políticos instituídos por representação de entidades governamentais e não governamentais, responsáveis por elaborar, deliberar e fiscalizar a implementação de políticas, estando presentes nas três esferas de poder. 
Dessa forma, inaugura-se nova concepção de espaço público ou mesmo de democracia.

A legitimidade desse sistema descentralizado e participativo fundamenta-se no reconhecimento da democracia participativa como espécie de arranjo institucional que amplia a democracia política e o espaço público. Por sua vez, a legitimidade da democracia participativa fundamenta-se no reconhecimento da importância da construção do espaço público de conflito/ negociação, ampliando os processos democráticos, não atuando em substituição ou oposição à democracia representativa, contudo enriquecendoa. (CANOTILHO; MORATO LEITE, 2011.p.183). A concepção do sistema descentralizado e participativo, como no caso dos conselhos e das conferências, que foi instituído na Constituição de 1988, relaciona-se à própria democratização e publicização do Estado, uma das possibilidades criadas para enfrentar a ausência de mecanismos eficazes de controle da população sobre os atos do Estado.

A participação acaba possuindo valor em si mesma. É a maneira pela qual as aspirações e as necessidades dos diferentes segmentos da população podem ser expressas no espaço público de forma democrática. Além disso, está associada ao modo como estes "grupos" se percebem como cidadãos e cidadãs. A participação é um processo educativo, em que se expressam desejos e necessidades, constroem argumentos, formulam propostas, escutam-se os outros pontos de vista; processo que visa a reagir, debater e chegar ao consenso; todas as atitudes que transformam os que integram processos participativos, em verdadeira educação republicana para o exercício da cidadania, que amplia um espaço público real, em que a construção dialogada do interesse público passa a ser o objetivo de todos (MORONI; CICONELLO, 2005); visando à conservação do meio ambiente, insere-se num quadro mais amplo da participação diante dos interesses difusos e coletivos da sociedade, sendo uma das notas características da segunda metade do século XX. A participação dos indivíduos e das associações na formulação e na execução da política ambiental foi uma nota marcante dos últimos vinte e cinco anos. Não se trata de uma classe profissional, mas de interesses que transcendem profissões e concernem a diversos segmentos sociais (diferença em relação aos sindicatos).

As políticas ambientais centradas apenas no pilar do "Comando e Controle", concebidas ao longo da década de 70, mostraram-se ineficientes porque visam à regulação de atividades de impacto ambiental negativo, o 
que representa alto custo e ineficiência administrativa quanto aos resultados obtidos (COSTA; BOEIRA; AZEVEDO, 2010). Nesse sentido, a participação e o engajamento da sociedade como um todo, a partir da diretiva constitucional do art. 225, caput, da $\mathrm{CF}$, acabou resultando num elemento estratégico para a tutela do meio ambiente.

O Estado Democrático Ambiental, tal como concebido por Canotilho (apud CARVALHO, 2008, p.119), possui uma limitação negativa, caracterizada na recusa à estatização/publicização do bem ambiental, à tecnização do direito (inclusão necessária dos cidadãos na discussão e confecção das normas ambientais) etc., e uma dimensão positiva, que o transforma num Estado Aberto, em que os cidadãos têm o direito de obter dos poderes públicos informações ambientais, em que as políticas de meio ambiente passa a ter um suporte generalizado, sendo dinamizadas por iniciativa de cidadãos, da sociedade civil organizada, valorizando-se e promovendo-se a participação dos cidadãos nos procedimentos administrativos ambientais, bem como na formação da legislação ambiental. Trata-se de um Estado que visa à Justiça Ambiental, em que vedada a iniqüidade e qualquer forma de discriminação ambiental nas decisões, seleções, práticas administrativas ou ações materiais que digam respeito à tutela ambiental (CARVALHO, 2008, p.19).

No caso do Brasil, o enfraquecimento da democracia representativa, em decorrência do próprio enfraquecimento do Estado Social, que em nosso país sequer se conseguiu implementar de maneira razoável, acaba empurrando a sociedade brasileira, dentro de sua acentuada policontexturalidade (beneficiada desde os primórdios da colonização por força das dimensões continentais do território brasileiro), para o aprimoramento da consciência cívica e da participação mais direta e efetiva nas tomadas de decisão. Paradoxalmente, os influxos do neoindividualismo, que advém do sucesso tardio da ideologia consumista tupiniquim, colocam em xeque o desenvolvimento dessa consciência cívica e dessa prática social. ${ }^{5}$

\footnotetext{
5 “[...], durante muito tempo, os instrumentos jurídicos internacionais limitavam-se a enunciar que as medidas ambientais a serem adotadas deveriam basear-se em posições científicas, supondo que este tributo à Ciência bastava para assegurar a idoneidade dos resultados. Esta filosofia inspirou a maioria dos convênios internacionais celebrados até o final da década de 80 , momento em que o pensamento sobre a matéria começou a mudar para uma atitude mais cautelosa e também mais severa, que levasse em conta as incertezas científicas e os danos às vezes irreversíveis que poderiam decorrer de atuação fundada em premissas científicas, que logo poderiam mostrar-se errôneas. Como exemplo disso, podemos citar a indústria do cigarro, poluição dos automóveis e efeito estufa." (RUIZ apud MACHADO, 2004, p.64).
} 
O princípio da precaução, segundo Hammerschmidt (2006), possui fases de aplicação bem nítidas, a primeira consistente na avaliação do risco, de caráter mais instrumental, perquirindo-se o fundamento objetivo ou 'científico' para as medidas precaucionais, aí devendo ser atendido o princípio da informação, e a segunda consistente na própria gestão do risco, de aspecto decisório, em que qualquer um com conhecimento razoável já possui condições de deliberar, em que ressalta o próprio fundamento político, com participação das autoridades públicas, sociedade civil e setor empresarial. A participação, encontra espaço nessa segunda fase ideal de aplicação do princípio da precaução, que está vinculado com o princípio da equidade intergeracional.

Enquanto princípio de direito ambiental, e na medida em que o direito ambiental está subsumido no princípio da dignidade humana, observada de forma mais ampla, poderia ser mesmo compreendido como sub-princípio desse valor maior. O princípio da participação está fortemente relacionado com os princípios fundamentais democrático e da dignidade humana; envolve a democracia participativa, ou seja, compreende a vontade popular na elaboração das decisões políticas, d entre elas, a ambiental, desde a sua origem; a Constituição Federal, no seu artigo 225, preconiza ação em conjunto da sociedade e do Estado na análise de objetivos e projetos de interesse ambiental.

A efetividade do sistema democrático, voltado para o consenso, alcança-se por meio de uma maior participação da sociedade e também tende a favorecer a preservação do meio ambiente, da biodiversidade, e a promoção da qualidade de vida, como propugna Arend Lijphart (2003, p.332).

A Constituição Federal, conforme acima aludido, lança os germens do princípio da participação em direito ambiental, ao lançar a expressão "[...] impondo-se ao Poder Público e à coletividade o dever de preservá-lo para as presentes e futuras gerações", no caput da art. 225. A legislação infraconstitucional, de maneira esparsa, insinua mecanismos que materializam de forma rarefeita o princípio da participação, como forma de gestão pública compartilhada. (BENTES, 2005). No entanto, o grau de fundamentalidade do princípio para o direito brasileiro é inquestionável. 


\section{A VERDADE CIENTÍFICA E AS RELAÇÕES DE PODER}

De acordo com o EDA, a gestão biotecnológica deve adotar critérios técnicos para a aferição dos riscos, mas deve ser feita juntamente com elementos políticos e supraindividuais para o estabelecimento de medidas compensatórias e preventivas diante das incertezas. O princípio da participação social vai de encontro à postura de entronizar "verdade científica", que omite o aspecto político na produção de conhecimento.

Segundo Michael Foucault (1999, p.17), ao analisar verdade e conhecimento, não há uma relação necessária entre o conhecimento e as coisas a conhecer, ou seja, o que se sabe a respeito de algo não é próprio de sua essência; ele não faz parte da natureza humana, não é algo que diz respeito à essência do homem, é algo inventado. O conhecimento "científico" é produto de relações de luta e engendrada no âmbito das relações de poder, cujos entrechoques pressupõem a política e por meio da política o próprio direito se constrói.

Foucault (2000) também analisa a constituição das ciências humanas tomando como ponto de partida a ideia de que, na verdade, a continuidade no nível das ideias representa apenas uma espécie de superfície, ao passo que, profundamente, num nível 'arqueológico', observa-se a ocorrência de uma mudança radical no século XIX, a partir do que as ciências humanas passaram a ser abordadas em perspectiva descontínua, por pressupor a ideia de representação.

Embora assim, a representação não é simples objeto das consciências humanas, mas o próprio campo das ciências humanas, e em toda a sua extensão; o aspecto geral dessa forma de saber, aquilo que a torna possível (FOUCAULT, 2000, p.509), o ser humano não tem historia porque fala, trabalha e vive, acha-se ele, em seu ser próprio, todo imbricado em histórias que não lhe são nem subordinadas nem homogêneas. Pela fragmentação do espaço onde se estendia continuamente o saber clássico, pelo enredamento de cada domínio assim liberado sobre seu próprio devir, o homem que aparece no começo do século XIX é 'desistoricizado'."

A tese de Foucault coloca em evidência o fato de que as ciências empíricas e a filosofia podem explicar o aparecimento desse conjunto de discursos denominados ciências humanas, pois é com elas que o homem passa a desempenhar duas funções diferentes e complementares no âmbito 
do saber: de um lado, é parte das coisas empíricas, na medida em que vida, trabalho e linguagem, são objetos que manifestam uma atividade humana; d'outro, o homem aparece como fundamento, como aquilo que torna possível aquele saber.

Para Foucault, o a priori histórico formado na modernidade decorre dessa dupla função do homem exercida pelo homem no saber, sua existência como coisa empírica e como fundamento filosófico, e é ele que explica o aparecimento das ciências humanas, do homem considerado não mais como objeto ou sujeito, mas como representação, o que explica o aparecimento das ciências humanas e as formas jurídicas.

É pela a arqueologia e a genealogia que Foucault (2005, p.172) analisa a discursividade local, a genealogia é a tática que, a partir da discursividade local assim descrita, ativa os saberes libertos da sujeição que emergem desta discursividade; o método arqueológico através da descrição do discurso apresenta-se como denúncia das regras que condicionam seu aparecimento; já o método genealógico se coloca como uma forma de resistência e de luta contra os discursos legitimados em determinada sociedade. Ele concebe a arqueologia como forma de descrever a constituição do campo, entendendoo como uma rede formada na inter-relação dos diversos saberes. E é exatamente nesta rede que se abre o espaço de possibilidade para a emergência do discurso. A genealogia, segundo Foucault, busca a configuração das positividades dos saberes a partir das condições de possibilidades externas a eles próprios, considerando-os como elementos de natureza estratégica. Procura-se a explicação dos fatores que interferem na sua emergência e adequação ao campo discursivo, defendendo sua existência como elementos de poder.

A genealogia serve para neutralizar a ideia que faz da ciência um conhecimento em que o sujeito vence as limitações de suas condições particulares de existência, pondo-se na neutralidade objetiva do universal, e, do outro lado, da ideologia um conhecimento impuro, em que o sujeito tem sua relação com a verdade perturbada, obscurecida, velada pelas condições de existência. Em realidade, todo o conhecimento, científico ou ideológico, só pode existir a partir de condições políticas, as mesmas para que se formem tanto o sujeito quanto os domínios do saber.

A investigação do saber não concebe um sujeito de conhecimento a origem do saber, mas a relações de poder que lhe constituem. Parte, sim, do pressuposto de que não há saber neutro, e todo ele é político, muito além do 
domínio do Estado, mas porque todo saber tem sua gênese em relações de poder.

A genealogia requer, então, a busca da singularidade dos acontecimentos, fazendo emergir os espaços excluídos ou esquecidos pelo discurso "verdadeiro". Trata-se, nesta análise, de considerar os saberes locais não legitimados ou valorizados pelo discurso verdadeiro - que, ao ocupar um lugar qualificado como científico, ordena, hierarquiza, classifica os diversos saberes.

O pluralismo jurídico contemporâneo encontra aqui seu fundamento, admitindo-se que para além do direito oficial há esferas na própria sociedade que também são responsáveis pela produção de direitos particulares. $\mathrm{O}$ próprio princípio da participação encontra aí reforço de seu fundamento. Com o reconhecimento do pluralismo jurídico, o Estado entra em processo de mutação, cedendo espaço a outros atores sociais, que são reconhecidos juridicamente como terceiro setor, e que passam a atuar diretamente na formação das políticas públicas e integrar instâncias de decisão. O Estado não é o único ou exclusivo produtor de direitos (apesar de formalmente o ser), pois a proposta pluralista admite que há uma diversidade de centros produtores, entendendo "direito" no sentido mais amplo do termo.

Foucault, por meio de seu questionamento da verdade científica, enfatizando o aspecto político na produção de conhecimento, reforça a ideia de que o cientificismo hermético, puro, deve ceder lugar ao pluralismo democrático, na gestão dos riscos de atividades que podem simplesmente levar a humanidade ao precipício de forma irreversível.

\section{O DISCURSO TECNICISTA/CIENTIFICISTA PREVALENTE NA LEI 11.105 DE 24 DE MARÇO DE 2005}

O exame das raízes do discurso prevalente durante o processo de elaboração da legislação de biossegurança permite sejam reveladas a sua inadequação ao princípio da participação social, no Estado Democrático de Direito.

O Brasil foi pioneiro na América Latina na consolidação, no âmbito do direito positivo, do "princípio de prevenção", o qual estabelece a obrigação de se evitar ou prevenir o dano ambiental quando esse puder ser detectado antecipadamente. A Lei de Política Nacional do Meio Ambiente, no seu artigo $10^{\circ}$, fundamenta tal princípio na exigência de realização de estudos 
de impacto ambiental (EIA) para o licenciamento de obras e atividades potencialmente poluidoras ou causadoras de degradação ambiental. Apesar de inovadora na defesa da preservação do meio ambiente, esta lei não faz qualquer conexão entre política ambiental e engenharia genética. Tal vínculo veio a ser estabelecido somente quando a Constituição de 1988 determinou ser obrigação do poder público "preservar a diversidade e a integridade do patrimônio genético do país e fiscalizar as entidades dedicadas à pesquisa e manipulação de material genético" (artigo 225, $\S 1^{\circ}$, inciso II, da Constituição Federal), como forma de fazer valer o direito de todos os brasileiros a "um meio ambiente ecologicamente equilibrado" (caput do artigo $225 \mathrm{da}$ Constituição Federal). Além disso, cerca de um ano após a apresentação do Projeto de Lei n. 114/1991, o Brasil, na condição de anfitrião da Rio-92, assinou a Convenção sobre Diversidade Biológica - a qual estabelecia, como vimos acima, a necessidade da preservação da diversidade genética. Nesse contexto, a primeira Lei de Biossegurança passou a incluir, em seu preâmbulo, o propósito de regulamentar "os incisos II e $\mathrm{V}$ do $\S 1^{\circ}$ do art. 225 da Constituição Federal".

As deficiências da primeira Lei Brasileira de Biossegurança (Lei ${ }^{\circ}$ 8.974/1995) começaram a vir à tona somente após o surgimento do primeiro pedido de liberação comercial de um alimento geneticamente modificado. Em junho de 1998, a sementeira multinacional Monsanto solicitou à Comissão Técnica Nacional de Biossegurança (CTNBio) - órgão vinculado ao Ministério da Ciência e Tecnologia (MCT), e legalmente responsável por avaliar os riscos relativos a pesquisas e comercialização de OGMs autorização para o cultivo comercial de sua soja transgênica Roundup Ready. ${ }^{6}$

Atendendo às pressões dos atores políticos críticos dos OGMs, o novo Projeto de Lei de Biossegurança (PL n. 2401 de 30 de outubro de $2004^{7}$ ), apresentado pelo poder Executivo, limitava significativamente a

\footnotetext{
${ }^{6}$ Antes mesmo do pronunciamento da Comissão, o Instituto Brasileiro de Defesa do Consumidor (IDEC), entidade da sociedade civil, associado a outras organizações, apresentou uma "contestação administrativa" à solicitação da Monsanto. A demora da CTNBio em dar uma resposta à tal contestação levou o IDEC, em liticonsórcio com o Greenpeace Brasil, a ajuizar uma ação civil pública (Processo n. 1998.34.00.027682-0), para impedir a União Federal de conceder autorização para plantio, comercialização e consumo da soja transgênica Roundup Ready sem a devida regulamentação da matéria e a realização prévia de Estudo de Impacto ambiental.

${ }^{7}$ Versão original disponível em http://www.camara.gov.br/proposicoesWeb/prop_mostrarintegra; jsessionid=DF07AEADE69B16B35DD090BC4EF74D46.node1 codteor=176917\& filename $=\mathrm{PL}+2401 /$ 2003.
} 
autonomia decisória da CTNBio na sua versão original. ${ }^{8}$ Segundo ao versão inicial, a CTNBio seria um órgão meramente consultivo, ao invés de deliberativo, e os pareceres técnicos desta Comissão vinculariam os OERF somente quando negativos - isto é, quando contrários à autorização da produção de um determinado OGM. Em casos de pareceres positivos da CTNBio, o IBAMA (MMA), a Anvisa (MS) e a Secretaria de Defesa Agropecuária (MAPA) poderiam realizar suas próprias avaliações complementares sobre dos pedidos de liberação.

Essa redução de poderes foi duramente criticada pelos grupos favoráveis à liberalização dos transgênicos, que propuseram que o parecer técnico da CTNBio voltasse a vincular os demais órgãos da administração, inclusive os OERF, quanto aos aspectos de biossegurança. As justificativas basearam-se no discurso de que a alternativa contrária, da proposição original, equivaleria a submeter a ciência a entraves burocráticos; tal burocratização, por sua vez, seria uma afronta à expertise dos cientistas - únicos aptos a tomar decisões sobre biossegurança. A burocratização do processo regulatório, com o re-empoderamento dos OERF, também foi considerada como equivalente à ideologização da regulação, em alusão ao contraste entre ciência e ideologia; ao invés de submeter os OGMs aos critérios objetivos da CTNBio, a nova Lei de Biossegurança estaria sujeitando uma questão científica e técnica ao irracionalismo político. (MITRE, 2011, p.146).

Ressaltam-se os esforços dos cientistas no sentido de diferenciar seu ofício não apenas da política, mas também de outras atividades que se pretendem científicas, a partir de um procedimento conhecido como boundary-making; este trabalho de demarcação de fronteiras estende-se também para o campo da própria ciência. Isto é, ele é feito não apenas para distinguir cientistas de não cientistas, mas também para resolver lutas por autoridade científica dentro da comunidade científica, desqualificar certos especialistas ou destituí-los de autoridade epistêmica; é comum recorrer ao que define como argumentos de "pureza", que reforçam a objetividade e neutralidade do especialista em questão, ou de "poluição", que atentam para a contaminação de seus pontos de vista pela não ciência. Além desta, havia uma distinção entre cientistas que trabalhavam para o governo e os que integravam os quadros das universidades, sendo os últimos considerados os mais "puros", muitas vezes tratados "como deuses" ou "árbitros" imparciais.

\footnotetext{
${ }^{8}$ Justificativa do PL 2401/2003, referido na nota anterior.
} 
Já os cientistas filiados ao governo seriam tachados de policy-makers, burocratas biológicos ou cientistas abaixo da média, trajados em um falso manto de certeza científica.

O texto aprovado no Congresso acabou novamente resultando vitória da CTNBio na disputa de poder com os OERF, ficando estabelecido que a CTNBio delibera, em última e definitiva instância, sobre os casos em que a atividade é potencial ou efetivamente causadora de degradação ambiental, bem como sobre a necessidade de licenciamento ambiental, como referimos na introdução.

É histórica a preocupação em detectar e superar as causas do suposto atraso do país com relação aos países do norte, marcada pela postura de pessimismo com relação ao povo brasileiro, geralmente considerado como o indolente culpado pelo "atraso"; muitos pensadores acabaram apegandose ao chamado "motivo edênico", ou à valorização da natureza do país, que em nada dependia do labor humano; em contraste às maravilhas da Europa, frutos da ciência e da razão humanas. O ímpeto de superar esta dicotomia, eliminando a dependência econômica e tecnológica do Brasil através do desenvolvimento da ciência, foi, historicamente um tema caro à esquerda. Neste sentido, não é coincidência a defesa da liberação dos OGMs com base no discurso sobre a necessidade de superar o subdesenvolvimento, a dependência e o obscurantismo, inclusive o religioso, através da promoção da ciência. Para além da disputa CTNBio x CNBS, o conflito ciência versus política também se manifestou na disputa pela composição da CTNBio, a qual por sua vez, tocou de maneira direta no tema da tensão entre expertise e democracia. (MITRE, 2011, p.154).

O primeiro projeto de lei de Biossegurança, apresentado em 1991, tinha a proposta de composição da CTNBio por quatro representantes de ministérios ou secretarias e três representantes de entidades civis ligadas ao desenvolvimento científico e tecnológico. Esta composição, que favorecia o "lado político" (mas não necessariamente democrático), em detrimento do lado "científico" da Comissão, passou a ser contestada logo no início do processo de tramitação. O primeiro relator do Projeto de Lei n.114/1991 no Senado, por exemplo, por sugestão da comunidade científica, não tardou em sugerir modificações na composição da CTNBio, no sentido de conferir mais poder aos cientistas e menos à sociedade civil . Como resultado, a primeira Lei de Biossegurança estabelecia que a CTNBio seria composta por oito especialistas de notório saber científico e técnico no segmento de 
biotecnologia ${ }^{9}$. Em contrapartida, o número de representantes de ministérios subiu para sete, ao mesmo tempo em que se instituiu a participação de representantes de entidades não governamentais.

A versão original do projeto de lei que foi transformado na vigente Lei n. 11.105/2005 favorecia o princípio da precaução e, consequentemente, dava mais peso à dimensão "política" da análise de biossegurança. Isso se traduziu, entre outras coisas, na proposta de que a CTNBio fosse composta por "vinte e seis cidadãos brasileiros," sendo dez "especialistas de notório saber científico e técnico" 10 , oito representantes de ministérios e nove representantes de entidades da sociedade civil. Vale notar que, entre os dez especialistas de notório saber científico e técnico, dois seriam da área de meio ambiente e dois das ciências sociais.

Durante a tramitação do projeto na Câmara, vários deputados favoráveis à desregulamentação dos OGMs apresentaram emendas no sentido de excluir os cientistas sociais da CTNBio, sob a justificativa de que seria necessário aumentar o peso da análise tecnicista, diminuir o número de leigos e, concomitantemente evitar a politização do processo decisório. Tais emendas, acatadas na própria lei aprovada, tinham por pressuposto de que as ciências sociais, por lidarem com a sociedade, não podem ser consideradas objetivas ou científicas, sendo sua própria denominação como "ciência" questionável. O argumento de defesa dessas emendas apelou não apenas para as credenciais destes últimos, mas também para traços de sua personalidade e conduta; é comum retratar alguns pesquisadores como pessoas sem interesses políticos, anti-sociais e até assexuadas, de forma a construir uma imagem dos mesmos como "seres" movidos unicamente pelo desejo de verdade (MITRE, 2011, p.156).

Além das bem-sucedidas tentativas de excluir cientistas sociais dos quadros da CTNBio, a fim de se evitar a "politização" do processo decisório, muitos defensores dos OGMs protestaram contra a noção de que a sociedade civil deveria ser representada na CTNBio, por tratar-se de assunto para experts, e não para o público em geral, menoscabando a importância da participação da sociedade civil, e se são importantes os aspectos socioeconômicos, não o são nessa instância; a instância decisória sobre a questão da segurança e sobre a questão científica deveria, conforme o

\footnotetext{
${ }^{9}$ Decreto $\mathrm{n}^{\mathrm{o}} 1.752$, de 20 de dezembro de 1995 , artigo $3^{\circ}$.

${ }^{10}$ Art. 10 do PL 2401/2003.
} 
discurso prevalente, ser prerrogativa dos cientistas. A noção de que ativistas, devido à sua experiência e interesse, poderiam ser encaixados na categoria de experts, mesmo que "não certificados", também chegou a ser refutada, ao contrário da tendência mundial de reconhecimento da expertise das ONGs. Isso contraria a qualificação dos quadros oriundos do terceiro setor, como adiante veremos no capítulo 3 deste trabalho. Alguns cientistas até chegaram a reconhecer a necessidade de abrir a CTNBio à participação da sociedade civil. Todavia, apontaram que o maior óbice a este caminho de democratização seria o próprio governo, não os cientistas. Pois, de fato, as indicações da sociedade, inclusive algumas científicas, são determinadas pelo Governo, que nomeia dezessete dos dezoito membros. É exatamente este o problema que tratamos no presente trabalho. (MITRE, 2011, p.158-9).

A versão final da vigente Lei de Biossegurança resultou bastante favorável às demandas da "comunidade científica" e dos grupos favoráveis à desregulamentação dos OGMs - tudo isso, é claro, dentro dos limites permissíveis pela cultura política brasileira. Apesar da exigência do título de doutor aos membros da CTNBio, e da substituição de "representantes de instituições" civis por "especialistas" - uma mudança de linguagem simbolicamente importante -, a nova lei manteve a possibilidade de realização de audiências públicas, por parte da CTNBio, previamente à liberação comercial de um OGM. Não podemos deixar de mencionar que o discurso tecnicista/cientificista prevalente na aprovação do texto da CTNBio, aliada à concentração de poderes deliberativos nas mãos desse colegiado, caracteriza uma espécie de releitura do Leviatã hobbesiano, numa tentativa estabelecimento de confiança que aposta numa neutralidade fantasiosa de um terceiro neutro e inteiramente "puro". Conforme, Robert Putnam, a coerção imparcial de um terceiro não constitui geralmente um "equilibrio estável", isto é, aquele em que nenhum jogador tem motivos para modificar o seu comportamento. (PUTNAM, 2006, p.175).

\section{ARRANJO INSTITUCIONAL CORRENTE DA CTNBIO: PREVALENCIA DO CIENTIFICISMO E DA AGENDA GOVERNAMENTAL EM DETRIMENTO DA SOCIEDADE CIVIL}

A composição da CTNBio constitui o retrato da prevalência do discurso cientificista, que esvazia o conteúdo do princípio da participação social. 
O funcionamento da atual CTNBio é definido a partir do art. 11 da Lei de Biossegurança (Lei n. 11.105/2005): “A CTNBio, composta de membros titulares e suplentes, designados pelo Ministro de Estado da Ciência e Tecnologia, será constituída por 27 (vinte e sete) cidadãos brasileiros de reconhecida competência técnica, de notória atuação e saber científicos, com grau acadêmico de doutor e com destacada atividade profissional nas áreas de biossegurança, biotecnologia, biologia, saúde humana e animal ou meio ambiente [...]" (grifo nosso).

Não obstante utilizar-se da expressão interdisciplinar, o rol taxativo de integrantes logo adiante contradiz o termo ao estabelecer que a CTNBio será composta de: 12 (doze) especialistas de notório saber científico e técnico, em efetivo exercício profissional, sendo: 3 (três) da área de saúde humana; 3 (três) da área animal; 3 (três) da área vegetal; 3 (três) da área de meio ambiente; 9 (nove) representantes indicados pelo ministros titulares do Ministério da Ciência e Tecnologia; Ministério da Agricultura, Pecuária e Abastecimento; Ministério da Saúde; Ministério do Meio Ambiente; Ministério do Desenvolvimento Agrário; Ministério do Desenvolvimento, Indústria e Comércio Exterior; Ministério da Defesa; Secretaria Especial de Aqüicultura e Pesca da Presidência da República; Ministério das Relações Exteriores; 6 (seis) vagas no terceiro setor compostas de um 'especialista em defesa do consumidor', indicado pelo Ministro da Justiça; um 'especialista na área de saúde', indicado pelo Ministro da Saúde; um 'especialista em meio ambiente', indicado pelo Ministro do Meio Ambiente; um 'especialista em biotecnologia', indicado pelo Ministro da Agricultura, Pecuária e Abastecimento; um 'especialista em agricultura familiar', indicado pelo Ministro do Desenvolvimento Agrário; um 'especialista em saúde do trabalhador', indicado pelo Ministro do Trabalho e Emprego.

Verifica-se, do arranjo institucional da CTNBio, que o colegiado foi dividido em três segmentos principais: os experts dos experts indicados "sociedades científicas", com direito a 12 (doze) mais cadeiras; os técnicos da "área governamental", com direito a 9 (nove), ou 3/4 das que são destinadas aos indicados das "sociedades científicas"; os representantes da "sociedade civil" organizada, com direito a 6 (seis) cadeiras, número equivalente metade das cadeiras destinadas às "sociedades científicas", e a 2/3 das cadeiras disponíveis aos indicados da "área governamental".

Cabe à sociedade civil organizada elaborar uma lista tríplice de mais votados, que serão escolhidos pelos ministros de cada pasta diretamente envolvida ( $§ 2^{\circ}$ do art. 11 da Lei de Biossegurança), o que vincula o sufrágio 
de forma determinante, pois o menos votado pode ser o escolhido, sem que, ao menos, haja alguma fundamentação para a escolha.

Conforme acima referimos, é difícil crer que um método de escolha cadeiras à sociedade civil condicionada ao aval de Ministros de Estado propicie a que haja efetiva representação da sociedade civil organizada nos quadros da CTNBio, a exemplo do ocorre em conselhos deliberativos análogos, como o Conselho Nacional do Meio Ambiente - CONAMA ${ }^{11}$, mas uma quase eleição de representantes - que não encontra regulamentação adequada no âmbito dos Ministérios - com escolha dentre os três mais votados por órgão do Poder Executivo, que pode condicionar a escolha.

O mesmo condicionamento aos "12 (doze) especialistas de notório saber científico e técnico, em efetivo exercício profissional” (art. 11, inc. I) não ocorre, podendo as "sociedades científicas" livremente escolherem seus representantes, sem a ingerência do Estado (art. 11, $\S 1^{\circ}$ ). As restrições às indicações das "sociedades científicas", inexistentes na lei de biossegurança, mostram-se quase nulas a partir do Decreto $n^{0} 5.591$, de 22 de novembro de 2005, regulamentador da Lei de Biossegurança, no artigo $6^{\circ}$. Nele, há a expressa previsão de que $O$ Ministro de Estado da Ciência e Tecnologia constituirá comissão 'ad hoc', integrada por membros externos à CTNBio, representantes de sociedades cientificas, da Sociedade Brasileira para o Progresso da Ciência - SBPC e da Academia Brasileira de Ciencias - ABC, encarregada de elaborar a lista tríplice de que trata o caput deste artigo, no prazo de até trinta dias de sua constituição.

Não há, no referido decreto, disciplina ou critérios mínimos sobre o foro adequado para a elaboração da lista tríplice dos representantes indicados pela sociedade civil organizada, ficando ao encargo de cada Ministério envolvido dispor, ou não, sobre os critérios próprios à indicação (art. $9^{\circ}$ do referido Decreto). A CTNBio não dispõe ou regulamenta sobre o processo de indicação dos representantes da sociedade civil, afirmando que o critério é estabelecido no âmbito de cada Ministério responsável pela indicação ${ }^{12}$.

Diante disso, procuramos obter informações junto aos Ministérios

\footnotetext{
${ }^{11}$ Decreto no 99.274, de 6 de junho de 1990, art. $5^{\circ}$.

12 Pedido de Informações n. 01390001067201319, feito ao Ministério da Ciência e Tecnologia, de acordo com a Lei de Acesso à Informação Lei $\mathrm{n}^{\circ}$ 12.527/2011: “[...] a articulação com as entidades da sociedade civil é de competência de cada um desses ministérios, cabendo ao Ministro do MCTI a nomeação da pessoa indicada pelos Ministros de Estado específicos."
} 
sobre os critérios para escolha dos representantes da sociedade, valendose da Lei de Acesso à Informação Lei $n^{0} 12.527 / 2011$. Especificamente, questionamos a forma como é feita a elaboração da partir de lista tríplice, quais entidades ou foro de entidades consultado para indicação e quais são os critérios de escolha específicos, de modo a determinar critérios específicos, além da personalidade jurídica, pertinência do objeto social com a especialização.

Nos pedidos de informações feitos de acordo com a Lei de Acesso à Informação, foram questionados o Ministério da Justiça (protocolo n. 08850004800201323), que afirmou realizar consultas públicas para escolha de integrante da CTNBio ${ }^{13}$, porém os critérios de escolha se resumem, efetivamente, à análise de currículo por parte do Ministério, por meio do que o órgão governamental elabora a lista tríplice, não ocorrendo nenhum tipo de eleição de membros; no pedido de informações feito ao Ministério da Agricultura, Pecuária e Abastecimento (protocolo n. 21900000355201358), transcreveu-se o conteúdo da legislação, nada sendo mencionado sobre utilização de mecanismo de consulta pública, havendo flagrante obscuridade de critérios para escolhas de representantes da sociedade civil, que, mais uma vez, está resumida à análise de currículos.

O Ministério da Saúde (protocolo n. 25820003997201350) informou que realizou consulta pública publicada no Diário Oficial da União em 29 de março e 22 de maio de 2012, com o objetivo de abrir prazo de 30 dias para apresentação de nomes ao processo de escolha desses membros da CTNBio, havendo indicações da Sociedade Brasileira em Genética (SBG), da Academia Brasileira de Ciências (ABC) e do Conselho Nacional de Segurança Alimentar e nutricional (CONSEA), a partir do que foi elaborada lista tríplice a partir de análise de currículo e procedida a indicação pelo Ministro da Saúde, Nenhuma ONG participou do processo e o método de escolha em pouco ou nada se diferencia dos "especialistas técnicos".

O Ministério do Desenvolvimento Agrário (protocolo n. 54800000987201307) informou que o processo de escolha foi feito pela Associação Brasileira de Agroecologia - ABA $^{14}$, designada para coordenar

${ }^{13}$ Consulta Pública n. ${ }^{\circ}$ 13/2008 do Ministério da Justiça, disponível em http://portal.mj.gov.br/ services/ Document Management/ FileDownload.EZTSvc.asp?DocumentID=\%7B7F1C016E-01D44ADB-8505-E92246A4B 75F\%7D\&ServiceInstUID=\%7B2E2554E0-F 695-4B62-A40E4B56390F180A\%7D.

REVISTA DO DIREITO PÚBLICO, Londrina, v.8, n.2, p.9-34, mai./ago.2013 
a elaboração das listas tríplices, destinadas a identificar especialistas em agricultura familiar, um titular e um suplente, para compor a Comissão Técnica Nacional de Biossegurança - CTNBio, dentro os quais será designado o representante da sociedade civil pelo Ministro. Os critérios para escolha não foram declinados de forma cabal, mas a participação ativa de um órgão de legitimação social para capitanear a elaboração da lista tríplice é mais confortante em termos de legitimação da escolha.

O Ministério do Meio Ambiente, (protocolo n. 02680.000935/201332) informou que realiza consulta às entidades da sociedade civil organizada, que elabora a lista tríplice dos indicados, sendo que o Ministro do Meio Ambiente "tem a liberdade de escolher um dos nomes a ser indicado". Na elaboração da listra tríplice, é o Ministério que, junto com o MDA, efetivamente consulta as organizações da sociedade civil, mas ainda "escolhe" com "liberdade" - leia-se, sem fundamentar a "escolha".

Em todas as informações prestadas pelos Ministérios que promovem a elaboração da lista tríplice e efetuam a indicação da sociedade civil, podemos ver que o processo seletivo não recorre a nenhum tipo de sufrágio, excepcionalmente ouve algum órgão de legitimação (exceção apenas ao MDA e do MMA), e a indicação dos integrantes da lista tríplice não possui critérios definidos, ficando ao arbítrio não fundamentado do Ministro da pasta. Em qualquer situação, vemos que o processo de escolha não atende ao princípio da participação, pelo menos de forma integral, o que gera sérios questionamentos sobre a legitimação desses representantes. Questionamentos de resposta óbvia: a metodologia demonstrada pelos ministérios agrava o discurso cientificista/tecnicista excludente, que permeou a elaboração da legislação de biossegurança e impede o estabelecimento da governança biotecnológica de acordo com o Estado Democrático Ambiental.

\footnotetext{
${ }^{14}$ Conforme a página a sua institucional "A Associação Brasileira de Agroecologia foi fundada em 2004, durante o II Congresso Brasileiro de Agroecologia. Desde então o número de associados está crescendo, assim como cresce nossa participação junto aos diferentes espaços em que a Agroecologia está se destacando como solução para a sustentabilidade da agricultura. Acreditamos que é fundamental a organização das pessoas que acreditam em um novo modelo de desenvolvimento e de agricultura, e para isso é fundamental que se juntam à ABA-Agroecologia. Muitas são ainda as frentes que precisam de atenção, e somente com a participação de todos'é que poderemos colaborar para que a Agroecologia assuma seu papel." Disponível em http://www.aba-agroecologia.org.br/aba/index.php/ sobre.
} 


\section{CONCLUSÃO}

Fizemos um breve exame dos discursos prevalentes na elaboração da legislação de biossegurança vigente, do arranjo institucional da CTNBio resultante e da forma como os Ministérios elaboram a lista tríplice e escolhem os representantes da sociedade civil, para concluirmos no final deste artigo que ainda há uma distância muito grande a ser percorrida para que seja atingida uma boa governança biotecnologia, em termos de participação social.

Para o que seria constitucionalmente exigível em termos de participação social, que deve ocorrer desde a gênese das políticas públicas em meio ambiente e em saúde pública, verifica-se que a composição da CTNBio estabelecida na lei e a partir dos critérios de escolha por parte dos Ministérios não atende ao princípio da participação; especialmente em razão do poder deliberativo que este órgão possui, pois lei estabelece a prerrogativa, dentre outras, de "a decisão técnica da CTNBio deverá conter resumo de sua fundamentação técnica, explicitar as medidas de segurança e restrições ao uso do OGM e seus derivados e considerar as particularidades das diferentes regiões do País, com o objetivo de orientar e subsidiar os órgãos e entidades de registro e fiscalização, referidos no art. 16 desta Lei, no exercício de suas atribuições".

O arranjo institucional da CTNBio, a sua composição, no que diz respeito à forma de escolha dos integrantes da sociedade civil organizada, não viabiliza de forma satisfatória a participação ampla, prevista na Constituição da República Federativa do Brasil de 1988, não atende a princípio estruturante do Estado de Direito Ambiental (ou Estado Democrático Ambiental), contraria a tendência mundial em favor do aprimoramento da participação social, conforme a Declaração Final da Cúpula dos Povos RIO+20 por Justiça Social e Ambiental em defesa dos bens comuns, contra a mercantilização da Vida, e a Rio+20 Declaration on Justice, Governance and Law for Environmental Sustainability, sendo contrária ao estabelecimento da boa governança ambiental. 


\section{REFERÊNCIAS}

BENTES, Genise de Melo. A implementação do princípio da participação na realização do projeto-pé-de-pincha: um estudo de caso. In:

CONGRESSO NACIONAL DO CONSELHO NACIONAL DE PESQUISA E PÓS-GRADUAÇÃO EM DIREITO, 14., 2005, Fortaleza. Anais... Fortaleza, 2005.

BOURDIEU, Pierre. Razões práticas: sobre a teoria da ação. 7.ed. Campinas: Papirus, 2005.

CANOTILHO, José Joaquim Gomes; MORATO LEITE, José Rubens, et al. Direito Constitucional Ambiental Brasileiro. 4. ed. São Paulo: Saraiva, 2011.

CARVALHO, Delton Winter de. Direito ambiental futuro: a responsabilização civil pelo risco ambiental. Rio de Janeiro: Forense Universitária, 2008.

COSTA, Ricardo Cunha da; BOEIRA, Rogério Londero; AZEVEDO, Caio Britto de. Perspectivas e desafios no setor de petróleo e gás. In: ALÉM, Ana Cláudia; GIAMBIAGI, Fabio. O BNDES em um BRASIL em Transição. Rio de Janeiro, 2010.

DERANI, Cristiane. Direito ambiental econômico. São Paulo: Max limonad, 1997.

FOUCAULT, Michel. A verdade e as formas jurídicas. Rio de Janeiro: NAU Ed., 1999.

. As palavras e as coisas. São Paulo: Martins Fontes, 2000.

. Microfísica do Poder. 21. ed. Tradução de Roberto Machado.

Rio de Janeiro: Graal, 2005.

HAMMERSCHMIDT, Denise. Transgênicos e Direito Penal. São Paulo: Revista dos Tribunais, 2006. (Série ciência do direito penal contemporânea, v.9). 
LIJPHART, Arend. Modelos de Democracia. Rio de Janeiro: Civilização Brasileira, 2003.

MACHADO, Paulo Afonso Leme. Direito Ambiental Brasileiro. 12. ed. São Paulo: Saraiva, 2004.

MITRE, Maya. Ciência e Política na era das novas biotecnologias: uma análise do marco regulatório brasileiro à luz de outras experiências. 2011. 259 fls. Tese (Doutorado em Ciência Política) - Faculdade de Filosofia e Ciências Humanas, Universidade Federal de Minas Gerais, Belo Horizonte.

MORATO LEITE, José Rubens; BELCHIOR, Germana Parente Neiva. O Estado de Direito Ambiental ea particularidade de uma hermenêutica jurídica. Sequência: Estudos Juridicos e Politicos, v.31, 2010.

MORONI, José Antonio; CICONELLO, Alexandre. Participação Social no Governo Lula: Avançamos? In: A ABONG nas Conferências 2005: Criança e Adolescente - Assistência Social. Brasília: Abong, 2005.

PUTNAM, Robert D. Comunidade e democracia: a experiência da Itália moderna. 5.ed. São Paulo: FGV Ed., 2006.

Recebido em: 2013-06-24 Aprovado para publicação em: 2013-08-14

Como citar: RIBEIRO, Christiano Dornelles; SCHIOCCHET, Taysa. A sociedade civil na composição da Comissão Técnica Nacional de Biossegurança: dificuldades para formação de uma governança biotecnológica. Revista do Direito Público, Londrina, v.8, n.2, p.9-34, mai/ago.2013. DOI: 10.5433/1980-511X.2013v8n2p9. 